\title{
Does a plant detect its neighbor if it is kin or stranger? Evidence from a common garden experiment
}

\author{
A. M. Abd El-Gawad1,3, M. Zotti², T. C. Sarker², S. Mazzoleni2, and G. Bonanomi² \\ IDepartment of Botany, Faculty of Sciences, Mansoura University, Mansoura 35516, Egypt \\ ${ }^{2}$ Department of Agricultural Sciences, University of Naples Federico II, via Università 100, 80055 Portici (NA), Italy \\ ${ }^{3}$ Corresponding author. Tel.: +201003438980; Tel.: +39081 2539015, Email: dgawad84@mans.edu.eg
}

Keywords: Plant kin recognition, Relative interaction index, Root allocation, Root architecture, Xanthium italicum.

\begin{abstract}
Unlike vagile organisms, plants perform a wide range of phenotypic responses to cope with environmental stresses. A special case of interaction with external factors is the ability of plants to recognize genetic relatedness of neighbour plants, actually well known as kin recognition. The present work aimed to provide a valuable contribution to the field of kin recognition in plants through a common garden experiment. To avoid bias involved in pot experiments, we perform an experiment in unconstrained root growth conditions comparing the development of coupled kin, non-kin and solitary plants of Xanthium italicum. Biometrics of plants with different genetic relatedness were measured, then architecture and competitive interaction were assessed using the relative interaction index (RII) for above and belowground portions of plants. X. italicum showed different allocation depending on the neighbourhood. Root biomass was declined in plants growing with kin compared to non-kin coupled plants, while plants coupled with kin allocated more shoot than roots compared to solitary plants. RII explains phenotypic response of decreased competition in roots rather than in shoots. Despite high values of RII for the aboveground portion, the architectural analysis of shoot, number, angle and length of branches and roots reveals dramatic but indistinctive change in the structure of plants growing near kin or non kin compared to a solitary plant. These results confirm phenotypic responses of kin recognition in unconstrained environment.
\end{abstract}

Nomenclature: Pignatti (1982).

Abbreviation: RII - Relative Interaction Index.

\section{Introduction}

Plants face a large variety of physical and chemical inputs both below- and above-ground. Particularly, as rooted organism, plants are forced to perform diverse phenotypic responses to ensure survival and successful gene propagation. Therefore, plants evolved sophisticated and complex strategies to monitor and process huge amount of information from the external environment (Guerrieri 2016). A special case gaining interest in plant perception of environmental stimuli is the ability to identify the genetic correlation of the other surrounding plants (Dudley and File 2007). The concept is based on the fact that plants, in their habitat, are closely surrounded by other plants that could be another species, a non-kin (strangers of the same species), kin (sibling) or clone (Wade 1980) which, in one way or another, interact and compete for available resources (Tokeshi 2009). Some researchers reported that plants performance is enhanced when growing near siblings, with respect to strangers (Willson et al. 1987, Tonsor 1989, Andalo et al. 2001, Donohue 2003, Collins et al. 2010). However, others have reported the opposite response (Escarre et al. 1994, Delesalle et al. 2002, Cheplick and Kane 2004, Milla et al. 2009), and many others found no significant effect (Schmitt and Ehrhardt 1987, McCall et al. 1989, Argyres and Schmitt 1992, Masclaux et al. 2010, Biernaskie 2011).
Recently, several studies have suggested that plants perform phenotypic changes when growing near other genetically related plants (Dudley and File 2007, Murphy and Dudley 2009, Bhatt et al. 2011). Given this, biomass allocation (Dudley and File 2007, Murphy and Dudley 2009, Bhatt et al. 2011, Marler 2013, Semchenko et al. 2014, Murphy et al. 2017), reproductive traits (Milla et al. 2009, Lepik et al. 2012), spatial disposition of leaves (Crepy and Casal 2015), physiological mechanisms (Biedrzycki et al. 2010, Biedrzycki and Bais 2011a), molecular patterns (Biedrzycki and Bais 2011b), as well as intra and inter-specific interactions (Ehlers et al. 2016) have been assessed with contrasting results (Lepik et al. 2012, Semchenko et al. 2017). However, with exception of work carried out by Karban et al. (2013) regarding the role of volatile emission in plant kin recognition, most of these studies were achieved in pot with laboratory or greenhouse settings, where conditions are far from that encountered under field conditions (Callaway and Mahall 2007). Therefore, in order to obtain more ecological relevant information about plants exposed to kin and non-kin neighbourhood, we carried out an experimental work in a common garden with Xanthium italicum as focal species. The aim of the work is to explore the net interaction effect as well as the phenotypic response of $X$. italicum through allocation (compartmentalization of biomass in plants) and spatial disposition depending on neighbours genetic relatedness. 


\section{Materials and methods}

$X$. italicum is an annual herbaceous plant belonging to Asteraceae with characteristic spiny fruits. X. italicum grows naturally in ruderal areas, roadsides, fallow, sandy soils linked to organic matter accumulation, and sandy coastal environments where it is among the species that represent the first form of colonization (Pignatti 1982). X. italicum seeds were collected from two different sites ( $\sim 2 \mathrm{~km}$ apart) at Cicerale village, southern Italy $\left(40^{\circ} 19^{\prime} \mathrm{N} 15^{\circ} 07^{\prime} \mathrm{E}\right)$. The seeds with homogeneous size and morphology were germinated on moist paper for $48 \mathrm{~h}$ at temperature of $26-28^{\circ} \mathrm{C}$. Once the radicle appeared, sprouted seeds with good vigour were planted directly into their final experimental area in April 2016. Work was conduced in an experimental area of the Department of Agricultural Sciences, University of Naples Federico II, Portici, Italy. Experimental area was divided into $100 \mathrm{~cm}^{2}$ plots separated from each other by $50 \mathrm{~cm}$ buffer zone. A total of 3 treatments were arranged: 1) Solitary plants 2) Kin, and, 3) Non-kin. The solitary treatment consists of one plant per plot, while the neighbor treatment (kin or non-kin) consisted of two plants per plot planted at $25 \mathrm{~cm}$ distance. The plots were randomly arranged with 4 replications for each treatment. The plants were watered ad libidum twice a week. After 114 days of transplantation, prior to harvest, all plants were tagged at soil surface in order to maintain correct identification of roots and shoots. Each individual plant was excavated from soil, signed for exact location, labeled for outside half (the side far from the neighbor) or inside half (the side face the neighbor) and transferred to the laboratory to take all measurements for root and shoot. Dry weight of shoot and root was measured for each individual. Moreover, number, length, and angle respect plant axis of branches and roots were determined by dividing the plant into two symmetrical halves, one that faced the neighbour and the other one that had no neighbour. Relative interaction index (RII) was measured for kin and non-kin combination as simple and accurate mathematical method to measure the strenght of interaction between two contiguos plant species. RII ranges from -1 to +1 with positive and negative values indicating competitive and facilitiative ineractions, respectively. The equation proposed by Armas et al. (2004) was modified as follows:

$R I I=\frac{B_{0}-B_{n}}{B_{0}+B_{n}}$

where, $B_{n}$ is the biomass of target plant growing with a neighbor, where the neighbor plants may be either kin (sibling) or non-kin (stranger) in our experiment. $B_{o}$ is the biomass of a target plant growing in absence of inter- or intraspecific interactions (solitary plants).

In order to assess main differences among biomass allocation and among morphological features in different treatments, analysis of variance (one-way randomized blocks ANOVA) based on Student test at $P=0.05$ probability level was performed using the COSTAT 6.3 program. To test the strength of competitive behaviour of plants paired with kin and non-kin, the significant differences of RII data were compared by paired two-tailed $t$-test using the XLSTAT 2014 pro- gram. The architecture drawing was carried out using Canvas 12 program.

\section{Results}

In the present study, the relative interaction index (RII) showed different effects in aboveground, belowground or whole plant with a positive (competitive) effect in plant-plant interactions (Fig. 1A). The aboveground parts of the plants showed significant variation in the intensity of competitive interaction between kin and non-kin plants $(P<0.01)$, while the belowground biomass did not show significant variation (Fig. 1A). However, the RII of the whole plant showed significant variation in competition between kin and non-kin $(P$ $<0.05)$. Solitary plants have increased growth, either root or shoot, with respect to kin and non-kin plants $(P<0.01)$. In de-
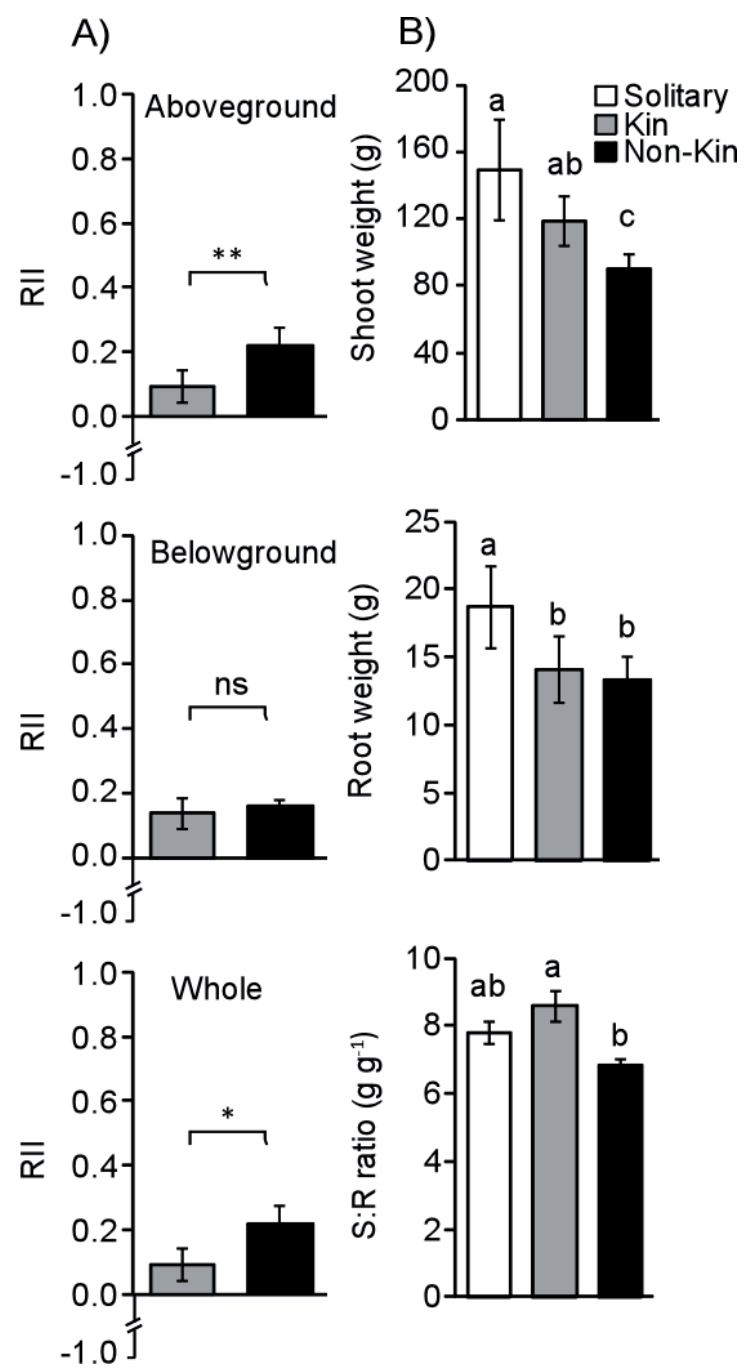

Figure 1. Xanthium italicum growth responds differentially to kin and non-kin under common garden condition. A) Relative interaction index (RII), and B) absolute weight of shoot and root, shoot:root ratio ( $\mathrm{S}: \mathrm{R}) .{ }^{*} P<0.05,{ }^{*} P<0.01$ (two-tailed t-test). Different letters per each histogram mean significant difference (one-way randomized blocks ANOVA). Data are mean value \pm $\mathrm{SE}(n=4)$. 

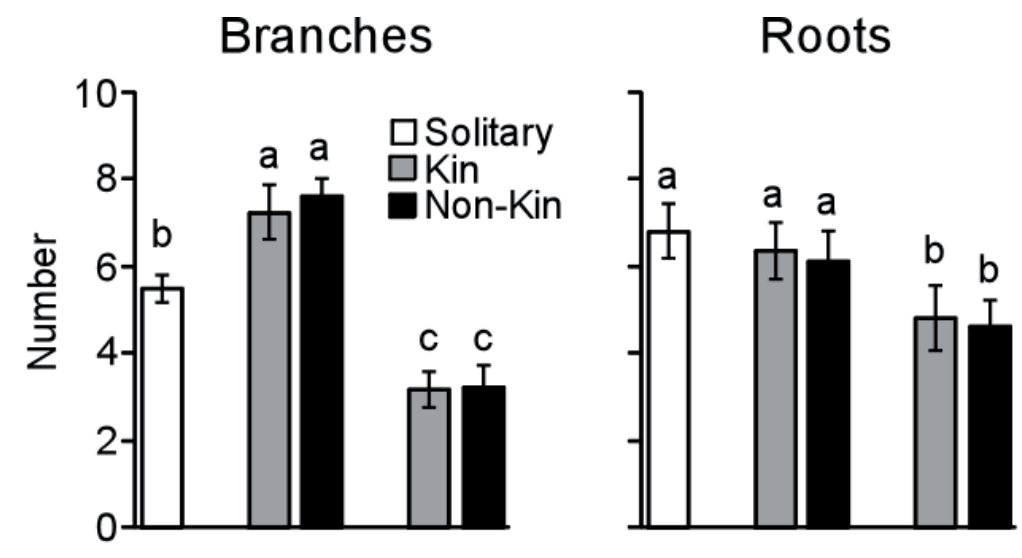

Figure 2. Xanthium italicum shoot and roots ramification analyses, responds differentially to kin and non-kin under common garden condition. "Out" means free neighbor side and "In" means neighbor exposed side. Different letters per each histogram mean significant difference (one-way randomized blocks ANOVA). Data are mean value $\pm \operatorname{SE}(n=4)$.
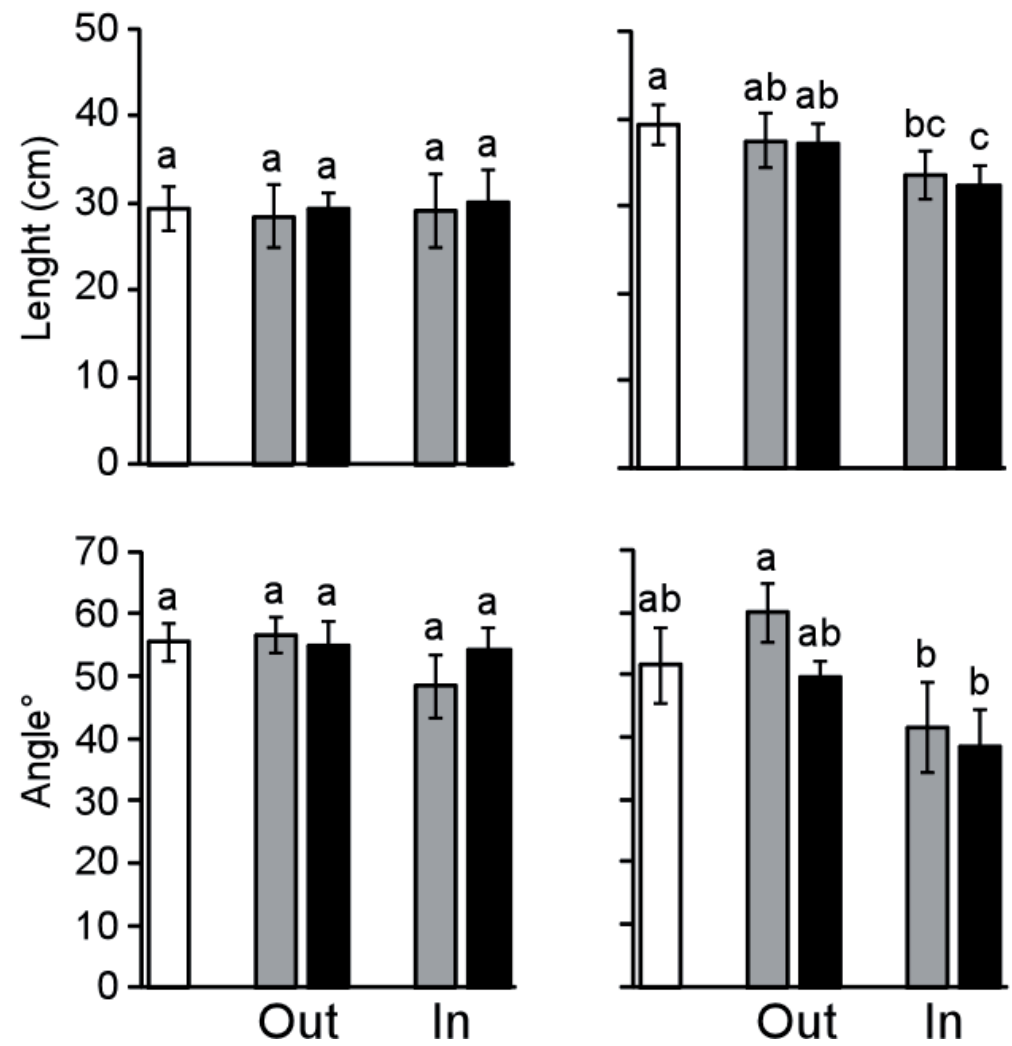

tail, kin plants are characterized by a significantly increased shoot biomass with respect to non-kin, while no significant difference was attested for roots of kin or non-kin (Fig. 1B). Moreover, the shoot/root ratio of the different plants showed significant variation in allocation between kin and non-kin treatments (Fig. 1B). Plants coupled with kin (sibling) allocated more shoot biomass than roots compared to solitary plants. Inversely, non-kin plants allocate more in belowground portion compared to solitary and kin neighboured plants (Fig. 1B).

Regarding plant architecture, no significant differences $(P<0.05)$ between kin and non-kin treatments for number, length, and angles of both secondary roots and branches were observed (Figs 2-3). However, both plants associated with kin and non-kin neighbour plants develop asymmetrical architecture, with respect to solitary plants (Figs 2-3). Moreover, no significant differences were recorded for the length and angle of the branches compared to solitary plants. Branch number of the inside half was reduced by $42.0 \%$ and $40.9 \%$ for kin and non-kin, respectively. In outside half, the number of branches significantly increased by $31.8 \%$ and $38.6 \%$ with respect to the solitary plants in kin and non-kin treatments, respectively. On the other hand, in belowground portion, number and length of secondary roots shows significant variation only in inside half $(P<0.05)$, while in the outside half no significant variation has been detected compared to the solitary plants (Figs 2-3). Regarding solitary plants, root angle of the inside half became narrower to the axis by $19.4 \%$ and $25.4 \%$ for kin and non-kin plants, respectively.

\section{Discussion}

The present results suggest that $X$. italicum is able to recognize kin neighbour in a common garden condition. This re- 
A

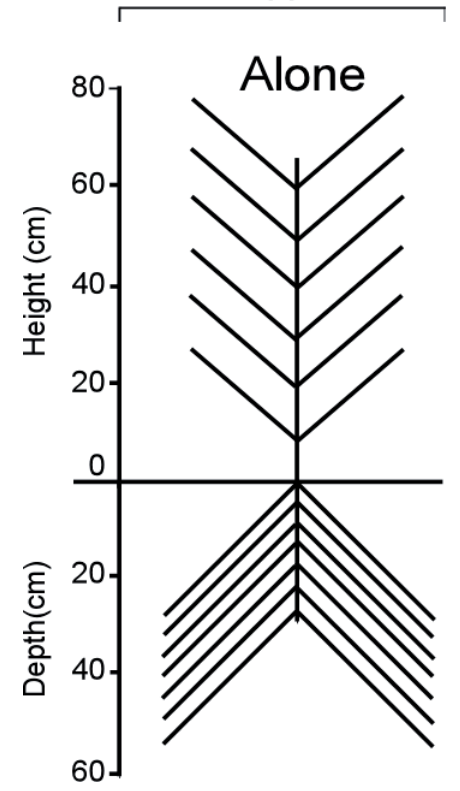

B

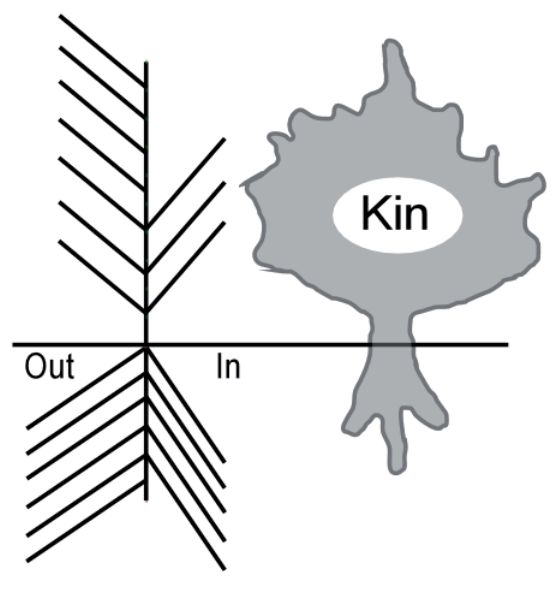

C

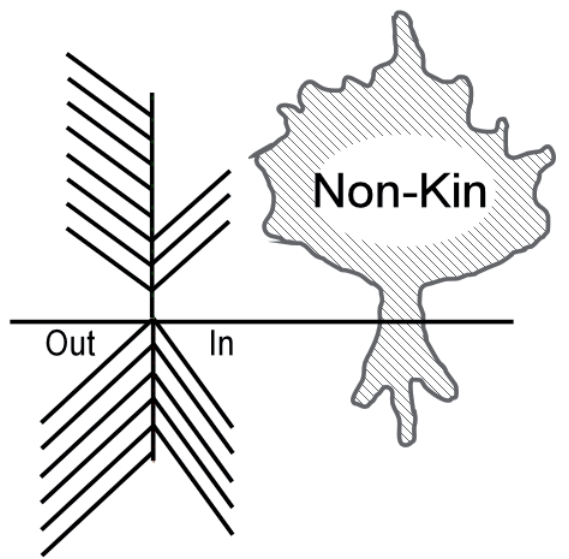

Figure 3. Xanthium italicum architecture drawing based on the biometric data showed the variation in the response toward kin or nonkin under common garden condition. A) solitary plant, B) plant growing with a kin (plants grown from seeds collected from the same mother plant), and C) plant growing with a non-kin (plants of the same species with different mother plants).

sult is consistent with pervious works describing kin recognition, although previous works were achieved in pots (Dudley and File 2007, Murphy and Dudley 2009, Chen et al. 2015, Dudley 2015).

In the case of $X$. italicum, the decrease in allocation toward belowground portion is matching the results achieved on Cackile edentula by Dudley and File (2007), but is in contrast with kin recognition experiments using Impatiens pallida that increases allocation towards aboveground portion (Murphy and Dudley 2009). As already hypothesized by Murphy and Dudley (2009), the divergence in results may lay in the different ecological characteristics of focal plants. In particular, $X$. italicum shares common ecosystem characteristics with $C$. edentula being common in highly disturbed environments. Therefore, both $X$. italicum and C. edentula developed enhanced competitive traits in root given the high light input available aboveground in its own ecosystems. Hence, results matching the idea that the competitive decrease induced by kin recognition takes place in organisms more responsive to resource fluctuations. As a matter of fact, in woodlands, light foraging competition became a prior mechanism selecting aboveground high competitive plants. This explains the decrease in allocation towards photosynthetic tissues in case of kin recognition of I. pallida as it is a woodland species (CidBenevento and Schaal 1986).

To further investigate kin recognition processes, we analyzed the architecture of aboveground portion of $X$. italicum. Interestingly, the aboveground portion was more responsive than belowground portion, allowing plants architecture to a dramatic change when growing in proximity of other plants. Despite the high interactive outcome in aboveground portion, no significant differences were assessed in length, number and angles between kin and non-kin compared to solitary plants. The results are not consistent with work based on relatives detection as factor regulating above ground portion morphology and disposition (Crepy and Casal 2015). Such discrepancy in results was conceivably endorsed to different plant traits between $X$. italicum and Arabidopsis thaliana. Indeed, the former is a semi-ligneous plant while the other is a non-ligneous one. As a consequence, the present study showed that rearrangement of aerial portion of semi-ligneous plants in presence of a neighbour might be attributed to a preferential strategy to avoid competition for light rather than a phenotypic response to relatedness of the neighbour.

Plants strongly affect biotic and abiotic characteristics of their own substrate via several processes (Van der Putten et al. 2013). Root exudation has been emphasized as one of the most important processes that influences the soil quality and thereby affects plant neighbors. In this consequence, kin recognition has been hypothesized to be a process mediated by root exudates (Biedrzycki et al. 2010, Semchenko et al. 2014). However, these works were carried out in a pots, with root constrains, where root exudation may be more effective (Margalef 1963, Callaway and Mahall 2007), leading to possibly over-emphasized results. Therefore, the arrangement of unconstrained experimental setting avoids the biases of works conduced in closed environments, exposing the phenomenon to the influence of stochastic interaction but decreasing the conditioning effect of the constrained environment (Callaway and Mahall 2007). Our results demonstrate that X. italicum is able to distinguish the relatedness of its neighbour, suggesting that the process of kin recognition is not only an over-expression of root exudates accumulation in constrained environment; neither is driven by conditioning effects of the plant 
on soil i.e., $\mathrm{pH}$ or nutrient depletion. Accordingly, our results allow us to hypothesize that kin recognition is a process mediated by the quality rather than the quantity of root exudates.

A novel evidence proposed by Mazzoleni and his co-authors showed that extracellular self-DNA appears to possess a range of unique signaling properties that could explain the mechanism of regulation of species coexistence and competition (Mazzoleni et al. 2015a,b, Cartenì et al. 2016). As we know that DNA acts as an individual-specific fingerprint, as well as it is exudated into the soil and persists for a long time. We speculate that it can potentially mediate recognition not only at the species level but also within species to distinguish kin from non-kin, i.e., the plant may sense the presence of its kin from its extracellular self-DNA. This effect, still not demonstrated, was discussed as relevant in the context of plant signaling (Varesoglou et al. 2015, Duran-Flores and Heil 2015)

\section{Conclusions}

Plant kin recognition and its contribution to plant coexistence patterns are still understood insufficiently, although several works demonstrate their ecological relevance (File et al. 2012, Lepik et al. 2012, Karban et al. 2013, Ehlers et al. 2016). Nevertheless, further evidence is required to understand the role and the actor of kin recognition in plants in light of that finding. Our results demonstrate that $X$. italicum recognizes its kin in common garden condition without root constrains. Kin plant becomes less competitive by changing its allocation strategy. Moreover, we hypothesize that kin recognition through root exudates is more plausibly a qualitative process than a quantitative one. However, further studies are needed to investigate the possible mechanism(s) and signaling components involved in plant kin recognition, especially under field conditions, which may provide insight to the clarification of kin recognition process.

Acknowledgments: We thank Dr. S. A. Gaglione and S. Spano for technical support in the common garden experiment.

\section{References}

Andalo, C., I. Goldringer and B. Godelle. 2001. Inter- and intragenotypic competition under elevated carbon dioxide in Arabidopsis thaliana. Ecology 82:157-164.

Argyres, A.Z. and J. Schmitt. 1992. Neighbor relatedness and competitive performance in Impatiens capensis (Balsaminaceae): a test of the resource partitioning hypothesis. Amer. J. Bot. 79:181-185.

Armas, C., R. Ordiales and F.I. Pugnaire. 2004. Measuring plant interactions: a new comparative index. Ecology 85:2682-2686.

Bhatt, M.V., A. Khandelwal and S.A. Dudley. 2011. Kin recognition, not competitive interactions, predicts root allocation in young Cakile edentula seedling pairs. New Phytol. 189:1135-1142.

Biedrzycki, M.L. and H.P. Bais. 2011a. The role of ABC transporters in kin recognition in Arabidopsis thaliana. Plant Signaling \& Behavior 6:1154-1161.
Biedrzycki, M.L. and H.P. Bais. 2011b. Transcriptome analysis of Arabidopsis thaliana plants in response to kin and stranger recognition. Plant Signaling \& Behavior 6:1515-1524.

Biedrzycki, M.L., T.A. Jilany, S.A. Dudley and H.P. Bais. 2010. Root exudates mediate kin recognition in plants. Communicative \& Integrative Biology 3:28-35.

Biernaskie, J.M. 2011. Evidence for competition and cooperation among climbing plants. Proc. Roy. Soc. London B: Biol. Sci. 278:1989-1996.

Callaway, R M. and B.E. Mahall. 2007. Plant ecology: family roots. Nature 448:145-147.

Cartenì, F., G. Bonanomi, F. Giannino, G. Incerti, C.E. Vincenot, M. L. Chiusano and S. Mazzoleni. 2016. Self-DNA inhibitory effects: underlying mechanisms and ecological implications. Plant Signaling \& Behavior 11:e1158381.

Chen, B.J., H.J. During, P.J. Vermeulen, H. Kroon, H. Poorter and N.P. Anten. 2015. Corrections for rooting volume and plant size reveal negative effects of neighbour presence on root allocation in pea. Funct. Ecol. 29:1383-1391.

Cheplick, G.P. and K.H. Kane. 2004. Genetic relatedness and competition in Triplasis purpurea (Poaceae): resource partitioning or kin selection? Int. J. Plant Sci. 165:623-630.

Cid-Benevento, C.R. and B.A. Schaal. 1986. Variation in population growth rate in the woodland annual Impatiens pallida (Balsaminaceae). Amer. J. Bot. 73:1031-1042.

Collins, A., E. Hart and J. Molofsky. 2010. Differential response to frequency-dependent interactions: an experimental test using genotypes of an invasive grass. Oecologia 164:959-969

Crepy, M.A. and J.J. Casal (2015). Photoreceptor-mediated kin recognition in plants. New Phytol. 205:329-338.

Delesalle, V.A., S.J. Mazer and S. Tonsor. 2002. The neighborhood matters: effects of neighbor number and sibling (or kin) competition on floral traits in Spergularia marina (Caryophyllaceae). Evolution 56:2406-2413.

Donohue, K. 2003. The influence of neighbor relatedness on multilevel selection in the Great Lakes sea rocket. Amer. Nat. 162:7792.

Dudley, S.A. 2015. Plant cooperation. AoB Plants 7, plv113.

Dudley, S.A. and A.L. File. 2007. Kin recognition in an annual plant. Biol. Lett. 3:435-438.

Duran-Flores, D. and M. Heil 2015. Growth inhibition by self-DNA: a phenomenon and its multiple explanations. New Phytol. 207: $482-485$.

Ehlers, B.K., P. David, C.F. Damgaard and T. Lenormand. 2016 Competitor relatedness, indirect soil effects and plant coexistence. J. Ecol. 104:1126-1135.

Escarre, J., C. Houssard and J.D. Thompson. 1994. An experimental study of the role of seedling density and neighbor relatedness in the persistence of Rumex acetosella in an old-field succession. Can. J. Bot. 72:1273-1281.

File, A.L., J. Klironomos, H. Maherali and S.A. Dudley. 2012. Plant kin recognition enhances abundance of symbiotic microbial partner. PLoS One 7:e45648.

Guerrieri, E. 2016. Who's listening to talking plants?. In: J.D. Blande and R. Glinwood (eds.), Deciphering Chemical Language of Plant Communication. Springer, Switzerland. pp. 117-136.

Karban, R., K. Shiojiri, S. Ishizaki, W.C. Wetzel and R.Y. Evans. 2013. Kin recognition affects plant communication and defence. Proc. Roy. Soc London B: Biol. Sci. 280:20123062. 
Lepik, A., M. Abakumova, K. Zobel and M. Semchenko. 2012. Kin recognition is density-dependent and uncommon among temperate grassland plants. Funct Ecol. 26:1214-1220.

Margalef, R. 1963. On certain unifying principles in ecology. Amer. Nat. 97:357-374.

Marler, T.E. 2013. Kin recognition alters root and whole plant growth of split-root Cycas edentata seedlings. HortScience 48:12661269

Masclaux, F., R.L. Hammond, J. Meunier, C. Gouhier-Darimont, L. Keller and P. Reymond. 2010. Competitive ability not kinship affects growth of Arabidopsis thaliana accessions. New Phytol. 185:322-331.

Mazzoleni, S., G. Bonanomi, G. Incerti, M.L. Chiusano, P. Termolino, A. Mingo, M. Senatore, F. Giannino, F. Cartenìand M. Rietkerk. 2015a. Inhibitory and toxic effects of extracellular self-DNA in litter: a mechanism for negative plant-soil feedbacks? New Phytol. 205:1195-1210.

Mazzoleni, S., F. Cartenì, G. Bonanomi, M. Senatore, P. Termolino, F. Giannino, G. Incerti, M. Rietkerk, V. Lanzotti and M.L. Chiusano. 2015b. Inhibitory effects of extracellular self-DNA: a general biological process? New Phytol. 206:127-132.

McCall, C., T. Mitchell-Olds and D.M. Waller. 1989. Fitness consequences of outcrossing in Impatiens capensis: tests of the frequency-dependent and sib-competition models. Evolution 43:1075-1084.

Milla, R., D.M. Forero, A. Escudero and J.M. Iriondo. 2009. Growing with siblings: a common ground for cooperation or for fiercer competition among plants? Proc. Roy. Soc. London B: Biol. Sci. 276:2531-2540.

Murphy, G.P. and S.A. Dudley. 2009. Kin recognition: competition and cooperation in Impatiens (Balsaminaceae). Amer. J. Bot. 96:1990-1996.

Murphy, G.P., R. Van Acker, I. Rajcan and C.J. Swanton. 2017. Identity recognition in response to different levels of genetic relatedness in commercial soya bean. Roy. Soc. Open Sci. 4:160879.

Pignatti, S. 1982. Flora d'Italia. Edagricole, Bologna, Italy.
Schmitt, J. and D.W. Ehrhardt. 1987. A test of the sib-competition hypothesis for outcrossing advantage in Impatiens capensis. Evolution 41:579-590.

Semchenko, M., S. Saar and A. Lepik. 2014. Plant root exudates mediate neighbour recognition and trigger complex behavioural changes. New Phytol. 204:631-637.

Semchenko, M., S. Saar and A. Lepik. 2017. Intraspecific genetic diversity modulates plant-soil feedback and nutrient cycling. New Phytol. 216:90-98.

Tokeshi, M. 2009. Species Coexistence: Ecological and Evolutionary Perspectives. Wiley, New York.

Tonsor, S.J. 1989. Relatedness and intraspecific competition in Plantago lanceolata. Amer. Nat. 134:897-906

Van der Putten, W.H., R.D. Bardgett, J.D. Bever, T.M. Bezemer, B.B. Casper, T. Fukami, P. Kardol, J.N. Klironomos, A. Kulmatiski and J.A. Schweitzer. 2013. Plant-soil feedbacks: the past, the present and future challenges. J. Ecol. 101:265-276.

Veresoglou, S.D., C.A. Aguilar-Trigueros and M.C. Rillig. 2015. Self-DNA: a blessing in disguise? New Phytol. 207:488-490.

Wade, M.J. 1980. An experimental study of kin selection. Evolution 34:844-855

Willson, M.F., W. Hoppes, D. Goldman, P. Thomas, P. KatusicMalmborg and J. Bothwell. 1987. Sibling competition in plants: an experimental study. Amer. Nat. 129:304-311

Received November 9, 2017

Revised December 4, 2017

Accepted December 26, 2017

Open Access. This article is distributed under the terms of the Creative Commons Attribution 4.0 International License (https://creativecommons.org/licenses/by/4.0/), which permits unrestricted use, distribution, and reproduction in any medium, provided the original author and source are credited, you give a link to the Creative Commons License, and indicate if changes were made. 